June 1-6: VIII European Rheumatology Congress, Helsinki.

October 3-4: Joint Meeting with Spanish Society of Rheumatology, Madrid.

November 28-29: The Heberden Oration. Annual General Meeting and Dinner, Royal College of Physicians, London.

\section{Submission of Abstracts}

All abstracts will be considered anonymously, that is without knowledge of the name(s) of the author(s) or the institution of origin, by the Executive Committee.

Members wishing to present original communications to the Society are therefore asked to prepare abstracts which provide sufficient information for assessing the paper on merit-an assessment which amounts to competitive selection between the various abstracts submitted.

In the preparation and submission of abstracts, the following points should be observed:

(1) Abstracts should not exceed 300 words. Each must be headed by a title, authors' names, institution and address.

(2) An actual summary of the communication is required. This will usually involve:

(i) A brief introduction to the work.

(ii) An outline of the methods used.

(iii) A summary of the results.

(iv) A statement of the main conclusions.

(3) Full references to previous work quoted must be given.

(4) Simple tables may be included. This is an excellent method of summarizing data.

(5) Accepted abstracts will be published as such with the proceedings of the Society in the Annals of the Rheumatic Diseases, so must be received in a form suitable for publication. In particular, statements such as "The data will be discussed" are entirely unacceptable. Abstracts may be revised for publication after the meeting.

(6) Abstracts should be sent to the Senior Honorary Secretary, The Heberden Society, c/o Arthritis and Rheumatism Council, Faraday House, 8-10 Charing Cross Road, London WC2. Abstracts received at least two weeks before each Executive Meeting (normally held on the same day as scientific meetings of the Society) will be assessed at that meeting.

(7) When submitting abstracts, authors must state whether the communication has been or is about to be read at another meeting; or has been or is about to be published.

(8) The normal length of time for presentation of papers is 10 minutes. However, if authors would prefer a longer ( 15 minutes) or shorter ( 5 minutes) time, this should be stated when submitting abstracts. The final allocation of time will however rest with the Executive Committee.

(9) Authors will be notified (i) when an abstract is received, (ii) when it is either accepted or rejected, (iii) when it is placed on a programme for a particular meeting.

(10) It is the author's responsibility to keep the Senior Hon. Secretary informed of the date of publication of any paper submitted to the Society.

\section{Clinical meeting}

The following papers were presented at the Annual General Meeting on November 1 and 2, 1974.

Interpreting the Biological Significance of Rheumatoid Factor. E. M. Badley, J. Ball, and P. H. N. Wood (A.R.C. Epidemiology Research Unit and Rheumatism Research Laboratories, University of Manchester)

Serological results are usually expressed as positive or negative. The simplicity of the resulting analysis is normally regarded as far outweighing the loss of information inevitably involved in dichotomizing the data. It is usually assumed that comparison of different results will be valid, whatever cut-off level is used. This can be justified statistically only if the cumulative titre distributions run in parallel. A hitherto unnoted exception to this generality can arise if the distributions intersect. This is the case when the rheumatoid factor (RF) titre distribution in the Rhondda is compared with those of Leigh and Wensleydale. Depending on the cut-off level chosen, Rhondda can have the most, the least, or an intermediate proportion of seropositive results.

Against this background the biological significance of RF can be assessed. Biologically the simplest test would be a link between RF positivity and death. The only fatal condition associated with seropositivity in the Rhondda was lung cancer; this observation has now been examined in Wensleydale as well, where no association was found. Thus the finding in the Rhondda could well be a chance finding, though we will need the results of a mortality follow-up in Leigh to confirm this.

Associations with various diseases and characteristics not leading to death are more difficult to interpret. Titres show some tendency to increase with age, but the pattern was not sufficiently consistent to warrant correction for age. Sex and occupation were without discernible effect. Comparison of the tests obtained 10 years apart on balance showed a reduction in titre, though tests unreactive on both occasions accounted for the majority of the results. Most persons in the community with a 'positive' test did not in fact have RA, nor were they likely to develop the disease. SCAT titres did not appear to be linked with smoking histories, bronchitis, respiratory tuberculosis (TB), blood pressure levels, or other risk factors for IHD such as cholesterol, although some relation with ECG abnormalities was found.

Rheumatoid Arthritis in the South African Negro. L. Solomon, P. Beighton, H. A. Valkenburg, and G. Robin (Epidemiological Research Unit, Department of Orthopaedic Surgery, University of the Witwatersrand, Johannesburg)

Rheumatoid arthritis, once thought to be rare in tropical and subtropical climes, has now been described in several African populations. However, its precise incidence and 